\title{
Specificity of evaluation management activities in logistics
}

\author{
Arina S. Astrakhantseva \\ Department of the public and municipal administration \\ Baikal State University \\ Irkutsk city, Russian Federation \\ arinasemail@gmail.com
}

\begin{abstract}
Issues of managing the commodity turnover of companies in general, and supply, in particular, are currently of concern to many researchers and managers. The article considers the most common approaches to assessing the effectiveness of logistics and supply management by the weighing method. The most common factors used in the analysis are considered. The author comments on various factors aimed at improving the efficiency of managerial decisions in the sphere of managing turnover and sales activities. The publication consistently reveals specific features of factor choice to assess the effectiveness of logistics activities for the Russian Federation and Irkutsk city. The author makes an attempt to adapt theoretical approaches to practical wishes of managers, based on the data obtained in the interview.
\end{abstract}

Keywords - supply, marketing, evaluation, efficiency, logistics, methods.

\section{INTRODUCTION}

Approaches to assessing the effectiveness of supply and sales activities in various organizations are a matter of interest for a significant number of specialists in this field. Many methods are based on both purely qualitative and quantitative methods of evaluation. Speaking about the correctness of the alignment of the evaluation trajectory, it is impossible not to mention those general-methodological principles on which it is necessary to build such research. In particular, the principle of systematicity, which involves considering all elements of supply and marketing activities as a set of interconnected elements, mentioned set determines not only the current state of the system, but also its future potential, based on the synergy effect. In other words, the logistics management concept implies the refusal to make decisions on the basis of a separate review of supply, sales, working with transport companies, a production program, etc. [1].

It has been practically proved that the effective interaction of the supply system elements has a significant effect on the effectiveness of marketing certain categories of material assets, which is caused by a variety of factors, both endogenous and exogenous. Among the latter, it is possible to distinguish the factor of foreign economic activity, incomes of the population, activity of consumer demand etc.
The errors made at the stage of analysis, planning of assortment of purchased products and, accordingly, organization of procurement and operational management of supplies and inventories, can not only undermine sales, but also lead to loss of target buyers, decrease in the organization's competitiveness for a long period[2].

When referring to internal factors, it is impossible not to affect the factor of the company's solvency, which in turn depends largely on the period of the stock inventory items turnover, the high level of which can significantly slow down the liquidity of the organization's balance.

The next principle, which is designed to stabilize approaches to the study of the operation effectiveness of supply and marketing evaluation activities, is the principle of science, based on the calculation strengthening in the research process. Practical implementation of this principle is impossible without the use of mathematical methods.

The undeniable importance, efficiency, understandability and ease of application of mathematical methods in assessing the effectiveness of various processes is proved and described in many sources of literature. Along with this, at present, many experts of the evaluation community show an increased interest in individual assessment methods, which take into account, for example, such aspects as behavioral and social, which in turn makes it possible to develop effective investment, financial, marketing and logistics strategies [3].

\section{THEORY}

One of the most popular and common methods applicable to assessing the effectiveness of supply-and-marketing activities is the weighing method. The popularity of this method is caused by the fact that at first consideration it has apparent simplicity and wide accessibility; however, the specificity and practical experience of using this method should be mentioned in more detail, since some stages of application of the method in the supply and marketing activities of enterprises are so ambiguous, which certainly require further consideration. 
The method is based on a fairly transparent algorithm of actions, which primarily includes the selection of those factors that will be evaluated, after which each factor is assigned a weight from 0 to 1 so that the sum of the weights does not exceed unity.

The next step is to multiply the factor estimates by the weights that were previously allocated, after which the values are summed up, the object with the largest amount is considered to be selected.

Consequently, the process of applying the method is conditionally reduced to selecting factors, selecting a scale of measuring the factors and assigning weight significance to each factor.

In the scientific literature there is no consensus on how to accurately and accurately choose the right and relevant to business environment factors that affect the state of the subject of analysis.Various issues recommend resorting to additional qualitative methods of factor analysis, attract experts in this field, whose practical experience is descriptively designated as a panacea for the negative outcome of incorrectly chosen factors.

In terms of assigning weights to the selected factors, the recommendations are largely similar and abstract, which puts researchers in an imminent impasse, as far current trends in accelerating the decision making process, building universal business management models, that are properly flexible and adaptable to changing environmental conditions, dictate the need to develop logically based solutions. Such solutions should build most faithful decision management, that leads to a positive outcome for the organization as a whole, and for the the decision maker in particular.

Reducing the timing of the management decision in the sphere of commodity circulation is the most important factor in shaping the effectiveness of commercial activity, ensuring timely satisfaction of the needs for a variety of goods while preserving their quality, reducing the costs of circulation and participating working capital, increasing the efficiency of all subjects of the commodity market [4].

Let us consider the most popular factors in the practical activity field, which can be chosen as the basis for applying the weighted method to supply activity effectiveness evaluation, among which we can distinguish the following: price, quality, profitability, commodity turnover.

\section{RESULT AND DISCUSSION}

These factors were identified as the most frequently used on the basis of studying applied materials related to the application of the considered method, provided by private companies, also in a survey form of supply and marketing departments heads of different companies in the Irkutsk city and the Irkutsk region, Russian Federation. Anticipated stages of management decision making process are described bellow
(Fig.1). At the same time, we should not forget that during the entire life cycle of the enterprise, there may be a large number of activities and there is a time for their modification under the influence of the current situation [5].

As a result of the interaction with the leaders of the above mentioned departments, about the method aplication, many referred to the fact that they use the criterion "price" solely because it is the most popular and in fact determining for the manager's decision. According to the company IFORS, conducted a study of consumer behavior of Russian customers, the price factor is the determining factor for $70 \%$ of buyers [6]. But some more detailed answer explaining the true essence was not obtained, this reason caused the necessary to consider those logical arguments that not only justified the recall of this factor, but also gave a certain detail.

In itself, the price of the acquired commodity-material valuesminds some amount of money, which, for example, a commercial wholesale company needs to give the producer of the procurement subject for the acquired commodity-material value, but is this factor complete?

With a high degree of probability, we can assume that it isnt, because the price of the subject of procurement does not include not only the cost of transporting the procurement proposal, but also the additional costs that the purchaser will incur while forwarding the purchased goods to the place of his subsequent resale.

In the price system, each individual price and each price group is in interrelation with all other prices. This is due to a single process of formation of production costs, interconnection and interdependence of the elements of the market mechanism of management and the actors operating in the market. The composition of the price is influenced by the taxation system, the social significance of goods, services, etc. [7].

Therefore, it is reasonable to include additional factors, such as "the seller's price", "the price at the entry point to the Irkutsk region", "the price at the place of destination (Irkutsk city)" or talk about the final value of the commodity-material value to the destination.

On the one hand, this may seem to be additional fractions that violate the integrity of the analysis, but on the other, in such countries as the Russian Federation, China, the United States of America, the indicated addition may become a decisive guarantee for the accuracy of the analysis, since in the Russian Federation a significant number of producers of goods of the people's consumption are located in the European part of the country, and the distance of transportation from this part of the continent, for example, to Irkutsk region exceeds 3000 miles; to some more distant regions of the Russian Federation - approximately 5000 miles. 


\section{Determination of the business}

\section{Evaluation purpose}

Quality and quantity of information

Determination of the factors influencing the object of evaluation

\section{Detailed consideration of the factor, clarification of the nature of its influence} (causcs, consequences)

Definition of possible subfactors

Determining the degree of subfactors influence (from weak to strong)

Assigning weights to each sub-factor, depending on the strength of influence

Assessment of the subfactors rating

General evaluation of factors rating

\section{Management decision-making}

Fig. 1. Anticipated stages of management decision making

The "quality" factor, which is also one of the allocated ones, is popular for practical application, it can be considered one of the most subjective, and subjectivism is the most vulnerable place of the analyzed method.

In order to reduce the degree of subjectivity, it is necessary to turn to what representatives of the regional business environment understand under the quality of commoditymaterial values.

The results of the survey showed that many entrepreneurs consider the product quality by the certificate of conformity existence and its compliance with the quality standards, but the complexity of the situation lies in the fact that the majority of, for example, food products produced in the Russian Federation are subject to mandatory certification. Therefore, in the evaluation process, all purchased goods that have a certificate of compliance, will be considered to be practically equivalent, it means that the factor "quality" will be equally appreciated on all products included in the analysis, which certainly affect the quality of the produced assay.

To decline the degree of negative impact of this factor, it is proposed to refine it. There is a significant amount of definitions of how the concept of "quality" is interpreted, for example, the representation of quality in the form of a subjective evaluation by the consumer, consumer properties of the product.

Proceeding from this, it can be assumed that the decisive value in the issue of quality determination is the final consumer's response to the subject of the purchase, in the process of the subsequent marketing. 
At this point the dependence between the efficiency of the sales system and the efficiency of the supply system is manifested to the highest degree. Assuming that the consumer's opinion is decisive, it is legitimate to consider the fact that the economic indicator reflecting the consumer reaction, will be the factor, that will most likely used effectively.

This indicator can be the billing received in the retrospective period from the sale of this category of goods, or the proceeds from other goods sold earlier, but produced by this manufacturer, etc.

Speaking about the "profitability" factor, it seems that this factor is so fundamental that it is impossible to disprove the need for its use in the process of practical analysis of the supply and marketing systems effectiveness, but is this really so?

In general, profitability is a complex indicator, since for its receipt it is necessary not only to have a retrospective account of the economic result of acquired commodity and material values sale, but also to take into account the level of costs that this process was accompanied.

The practice of applying theoretical methods in an active business environment, according to the heads of supply and marketing services interviewed in the process of conducting a study, indicates that the most rapidly reacting to changes in the external environment are subject-matters, which are the simplest ones that consist of one or two-element-stages.

Therefore, it is legitimate to say that despite the strength of the "profitability" factor, the complexity of it, and the impossibility of obtaining data to fill its calculation, provided by the fact that the time for making a management decision is limited, really makes it difficult to apply it in practice, reduces the effectiveness of the application of the weighting method, increases the processing time of information and does not give the effect that managers would like to see. Professor of Baikal State University Kolodin V.S. argues that a decrease in the cost of purchased products by $5 \%$ could lead to an increase in profitability by more than $30 \%$ [8].

As a result, it is proposed to present a number of economic indicators, the ratio of which relative to each other and is a measure of profitability individually or completely.

Let us consider the factor "costs" in more detail. The indicated factor is so extensive that the decision making about what kind of costs will be included in the list of costs already makes it difficult to choose. To simplify the solution of this issue, it is proposed to distinguish two main types of logistics costs: storage costs and transportation and procurement costs.

In the opinion of Kazarina L.A., cost division, focused on basic operations, allows solving the problems that often arise with the use of traditional methods of cost distribution, and, accordingly, facilitates the development of performance criteria and provides an opportunity to identify areas for improvement [9].

Thus, the process of accounting the factors affecting the effectiveness of the functioning of the supply system of the organization will become more accessible, and the processing speed of information will increase at times.Concerning the concept of "commodity turnover", it is also possible to add some negative aspects that can introduce confusion in the process of analyzing the effectiveness of supply and marketing systems.

Commodity urnover is an indicator measured in monetary terms, and consequently largely depends on what was the price of the sales target at the time of its acquisition, what was the exchange rate, at the time of the transaction, etc. By the way, in Russian Federation in 2016, the total turnover of organizations for all types of activities amounted to 149320.2 billion rubles, of which 56581.1 billion rubles - turnover of wholesale and retail trade [10].

\section{CONCLUSION}

If the analyst is faced with the task of assessing the effectiveness of the supply or sales system over a number of years, this indicator can significantly distort the result of analytical work, since in many countries the exchange rate and the real purchasing power of money are variable. In order to see a more clear picture of the material flow, it is proposed to use the concept of "turnover of goods" in the analysis. This concept can be considered more stable, since the freight turnover is calculated in tonne-kilometers, which can be taken as natural expression, it means, despite the change in financial indicators, the researcher will always see the real dynamics of the change in the velocity and volume of material flow movement. Speaking about approaches to assessing the effectiveness of supply systems and marketing of various organizations, we can not fail to mention that the process of supplying and providing material and technical resources is present in almost any organization. The only difference is that for some organizations, this business process is the main business process, and for others it is an accompanying business process.

Regardless of which process is the supply process for the focus company, it is necessary to do systematic monitoring of the supply system performance evaluation in production, and commercial companies, and public sector organizations as well.

Of course, each organization has its own specific activities and requires an individual approach, but there are common indicators such as performance and competitiveness, which are currently unite all types of organizations, with the need to find effective solutions to the mentioned tasks.

\section{References}

[1] A.O. Bezmaternykh, E.V. Fayzrakhmanova, "Creating a balanced scorecard for effective management decisions," Competitiveness in a global world: economics, science, technology, vol. 12 (part 13), pp. 1634-1637, 2017.

[2] V.I. Burakov, "Principles and methods of logistic management of industrial enterprises," Bulletin of Irkutsk State Economics Academy, vol. 2, pp. 15-18, 2013.

[3] Yu.N. Gorpinyuk, "The feasibility of applying mathematical techniques to the valuation," Young scientist, vol. 14, p. 243-246, 2015. 
[4] L.A. Kazarina, "Management decision-making on the basis of activitybased costing approach in logistics cost accounting," Bulletin of Irkutsk State Economics Academy, vol. 26, no. 3 (89), pp. 66-70, 2013.

[5] V.S. Kolodin, Ya.M. Bystritskaya, "Logistical factors influencing the Russian retailing development," Izvestiya of Irkutsk State Economics Academy, vol. 25, no. 1, pp. 95-102, 2015.

[6] G.V. Maklakov, "Time as an economic category in the field of commodity circulation," Siberian financial school, vol. 1(114), pp. 11$15,2016$.

[7] N.G. Novikova, "Factor analysis of assortment management results in the organization's supply chain and its competitiveness (by the example of retail service)," Bulletin of Irkutsk State Economics Academy, vol. 26, no. 2, pp. 274-283, 2016.

[8] Official website of "Marketing Agency Marketingservis" www.marketing-services.ru
[9] Russian Statistical Yearbook 2017: Stat .book/Rosstat, 2017, 686 p.

[10] I.N. Shcherbakova, "Russia's price policy in current terms," Baikal Research Journal, vol. 8, no. 2, pp. 12-24, 2017. 